\title{
RANCANG BANGUN ALAT PEMIPIH BIJI JAGUNG OLAHAN
}

\author{
Simon Ka' ${ }^{1}{ }^{1}$, Jeremiah Ritto ${ }^{1}$, Hasni ${ }^{2}$, Mario F.L.N Juanto ${ }^{2}$, Ghiyats Dzulkifli $\mathbf{M}^{2}$
}

\begin{abstract}
Abstrak: Jagung merupakan salah satu hasil pertanian di indonesia yang memiliki banyak kandungan gizi. Untuk memanfaatkan jagung tersebut maka dibuatlah alat pemipih biji jagung yang dapat dimanfaatkan di kalangan masyarakat. Pembuatan alat yang sebelumnya telah dibuat dengan ketebalan $\pm 1,0 \mathrm{~mm}$. Oleh karena itu, pembuatan alat ini dilakukan untuk mengetahui bagaimana menghasilkan pemipihan jagung yang ketebalannya bervariasi $\pm 1, \pm 1,5$ dan $\pm 2 \mathrm{~mm}$, membuat alat pemipih jagung yang minimalis dan mudah dioperasikan serta bagaimana mengetahui biaya pembuatan alat pemipih biji jagung olahan ini. Berdasarkan hasil pengujian hasil pemipihan yang diperoleh untuk ketebalan $\pm 1,0 \mathrm{~mm}$ yang diambil dari 10 sampel pengujian yang diambil secara acak yakni rata - rata $1,01 \mathrm{~mm}, 1,08 \mathrm{~mm}$, dan 1,07 mm selama 3 kali percobaan. Sedangkan hasil pemipihan yang diperoleh untuk ketebalan $\pm 1,5 \mathrm{~mm}$ yang diambil dari 10 sampel pengujian yang diambil secara acak yakni rata - rata 1,52 mm, 1,62 mm, dan 1,56 mm selama 3 kali percobaan. Serta hasil pemipihan yang diperoleh untuk ketebalan $\pm 2,0 \mathrm{~mm}$ yang diambil dari 10 sampel pengujian yang diambil secara acak yakni rata - rata 2,09 mm, $2,02 \mathrm{~mm}$, dan 2,05 $\mathrm{mm}$ selama 3 kali percobaan.Adapun hasil dari analisis, maka waktu pengeringan berpengaruh pada waktu proses pemipihan, dimana menunjukkan bahwa semakin lama di jemur semakin cepat proses pemipihan dan sedikit berpengaruh pada hasil pemipihan.
\end{abstract}

Kata Kunci: Jagung, Ketebalan, Pemipihan, Pengeringan

\section{PENDAHULUAN}

Jagung merupakan salah satu produk pertanian yang mempunyai nilai gizi dan serat kasar yang cukup tinggi, serta satu siklus hidupnya diselesaikan dalam 80-150 hari. Oleh karenanya komoditas ini cukup memadai untuk dijadikan makanan pokok manusia maupun ternak.Jagung merupakan tanaman pangan yang mengandung manfaat untuk kesehatan.Upaya peningkatan produksi jagung sebagai salah satu bahan pangan diantaranya dengan melakukan proses pengolahan pasca panen. Selain untuk memperpanjang daya tahan penyimpanan dan pemanfaatannya, pengolahan pasca panen ini juga berfungsi untuk meningkatkan nilai jual jagung.Untuk mendapatkan mutu jagung yang baik dan bermutu tinggi tidaklah mudah.

Hal ini disebabkan oleh penanganan pasca panen yang kurang tepat, kurang efisien, boros waktu dan tenaga kadangkala hasilnya masih kurang baik. Secara umum, emping merupakan produk olahan pangan dari bahan berpati yang dipipihkan menjadi lempengan dengan bentuk tertentu dikeringkan, dan digoreng renyah. Adapun masalah yang dihadapi yakni bagaimana menghasilkan pemipihan jagung yang ketebalannya bervariasi $+1, \pm 1,5$ dan $\pm 2 \mathrm{~mm}$ dan bagaimana menghitung biaya pembuatan alat pemipih biji jagung olahan. Perancangan ini bertujuan untuk menghasilkan ketebalan pemipihan jagung yang bervariasi dan untuk mengetahui total biaya pembuatan alat pemipih biji jagung olahan. Adapun manfaatnya yaitu mempermudah penanganan pasca panen jagung, mengurangi biaya pengelolahan, memudahkan dalam pengerjaan, memberikan kesempatan bagi masyarakat menengah kebawah untuk mencoba memulai usaha kecil - kecilan.

\section{METODE PENELITIAN}

Kegiatan Perancangan Alat pemipih jagung dari tahap persiapan dan Study kelayakan, pembuatan draft perancangan, analisa perancangan, desain gambar, pengujian dan analisa hasil sampai pembuatan laporan hasil. Kegiatan perakitan alat dan pengujian alat dilaksanakan dibengkel Jurusan Teknik Mesin.

Untuk mempermudah proses rancang bangun ini maka dibuatlah aliran proses rancang bangun mesin pemipih biji jagung olahan dalam bentuk diagram alir seperti dalam gambar berikut:

\footnotetext{
${ }^{1}$ Staf Pengajar D4 Jurusan Teknik Mesin Politeknik Negeri Ujung Pandang

${ }^{2}$ Alumni Jurusan Teknik Mesin Politeknik Negeri Ujung Pandang
} 
5 Simon Ka'ka, Jeremiah Ritto, Hasni, Mario F.L.N Juanto, Ghiyats Dzulkifli M. Rancang Bangun Alat Pemipih Biji Jagung Olahan

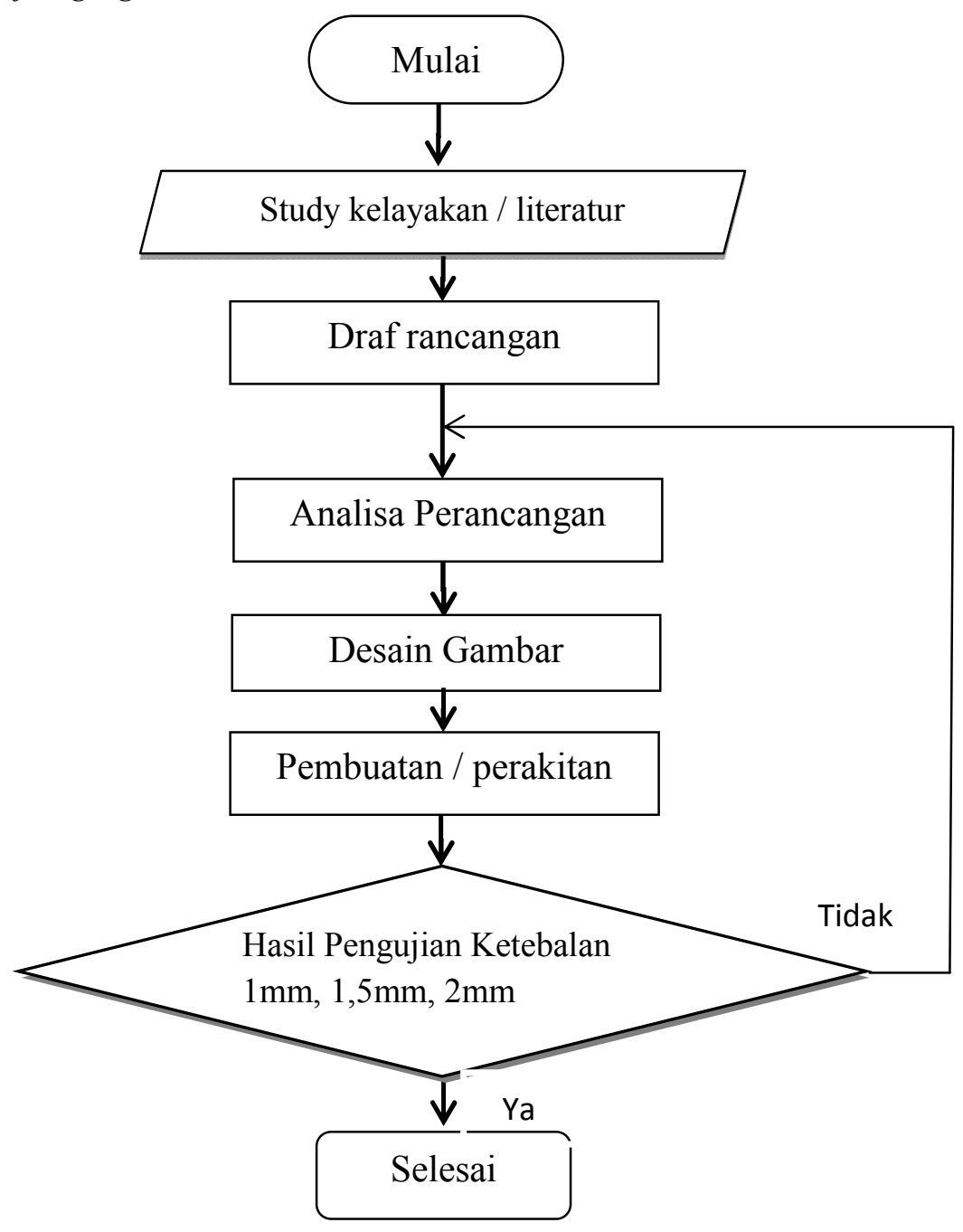

Gambar 1. Diagram perencanaan

Prinsip kerja alat ini yaituputaran motor (1) sebesar 2800 rpm melalui pully(3) dan V-belt (4) direduksi putarannya oleh reduser (2) menjadi $875 \mathrm{rpm}$ dan melalui pully, putaran diteruskan ke roll pemipih (5) dan putaran roll, berlawanan arah dengan bantuan roda gigi (6). Jagung yang terpiph setelah melalui roll pemipih jatuh di penadah (8) dan rangka (9) mesin mampu menopang semua berat bagian - bagian mesin. Adapun gambar rancangan alat ini sebagai berikut. 


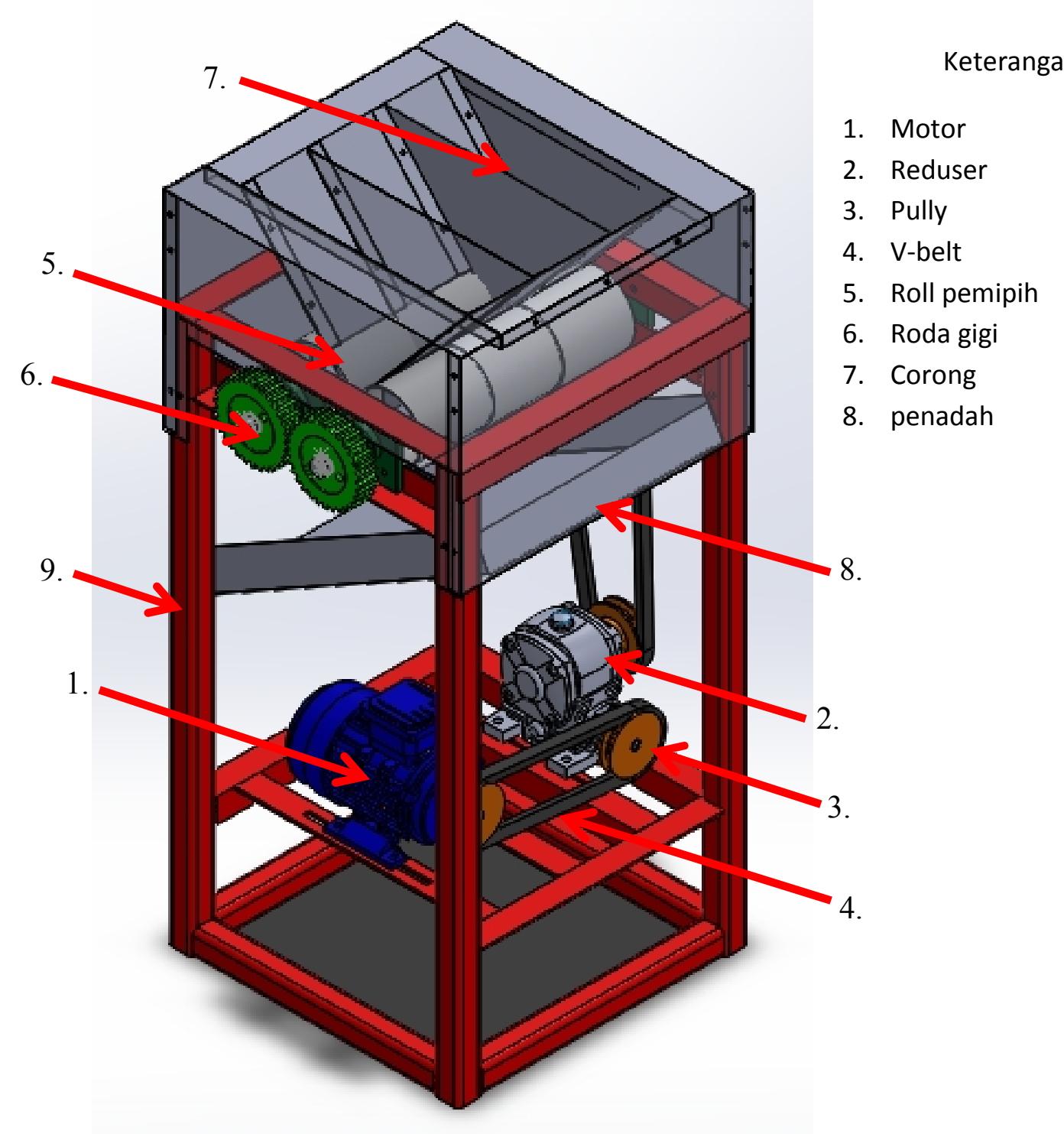

Gambar 2. Mesin Pemipih Jagung Olahan

\section{HASIL DAN PEMBAHASAN}

Sebelum dilakukan proses pengujian jagung terlebih dahulu direbus selama 2 jam, 4 jam dan 6 jam. Sebelum digoreng jagung dikeringkan selama 3,5 jam untuk menghilangkan sebagian kadar air yang terkandung dalam jagung. Adapun hasil yang diperoleh dari proses pengujian sebagai berikut : 
7 Simon Ka'ka, Jeremiah Ritto, Hasni, Mario F.L.N Juanto, Ghiyats Dzulkifli M. Rancang Bangun Alat Pemipih Biji Jagung Olahan

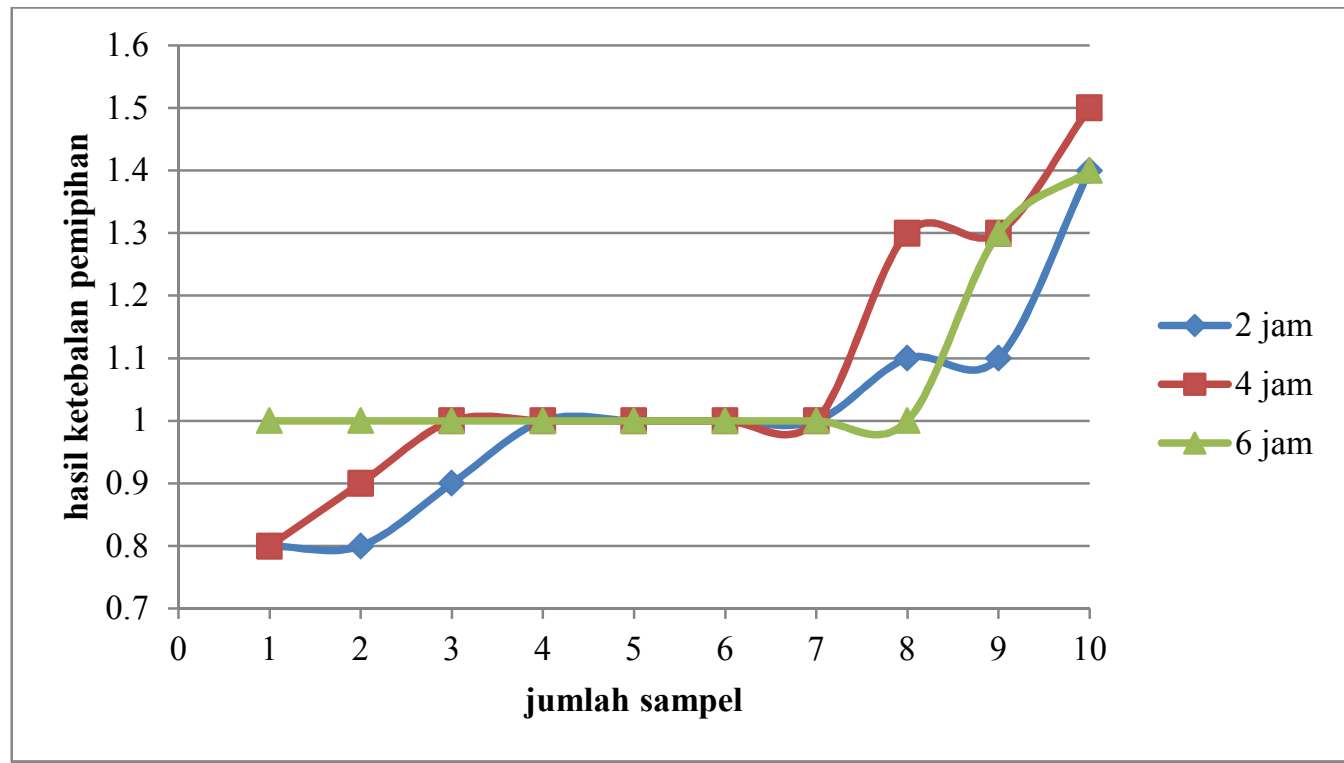

Gambar 3. Grafik hasil proses pemipihan untuk ketebalan $\pm 1 \mathrm{~mm}$ selama 2 jam, 4 jam, dan 6 jam.

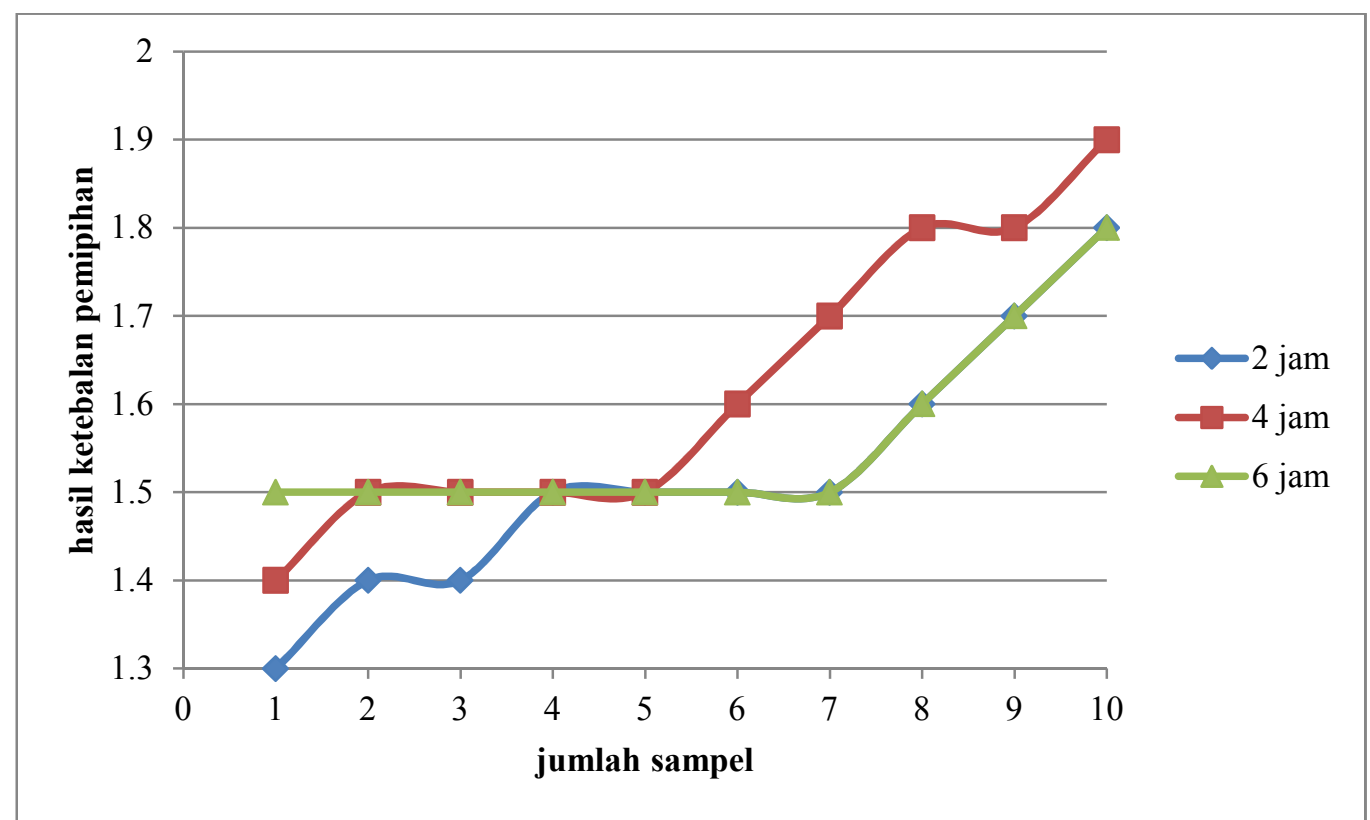

Gambar 4. Grafik Hasil proses pemipihan untuk ketebalan $\pm 1,5 \mathrm{~mm}$ selama 2 jam, 4 jam, dan 6 jam. 


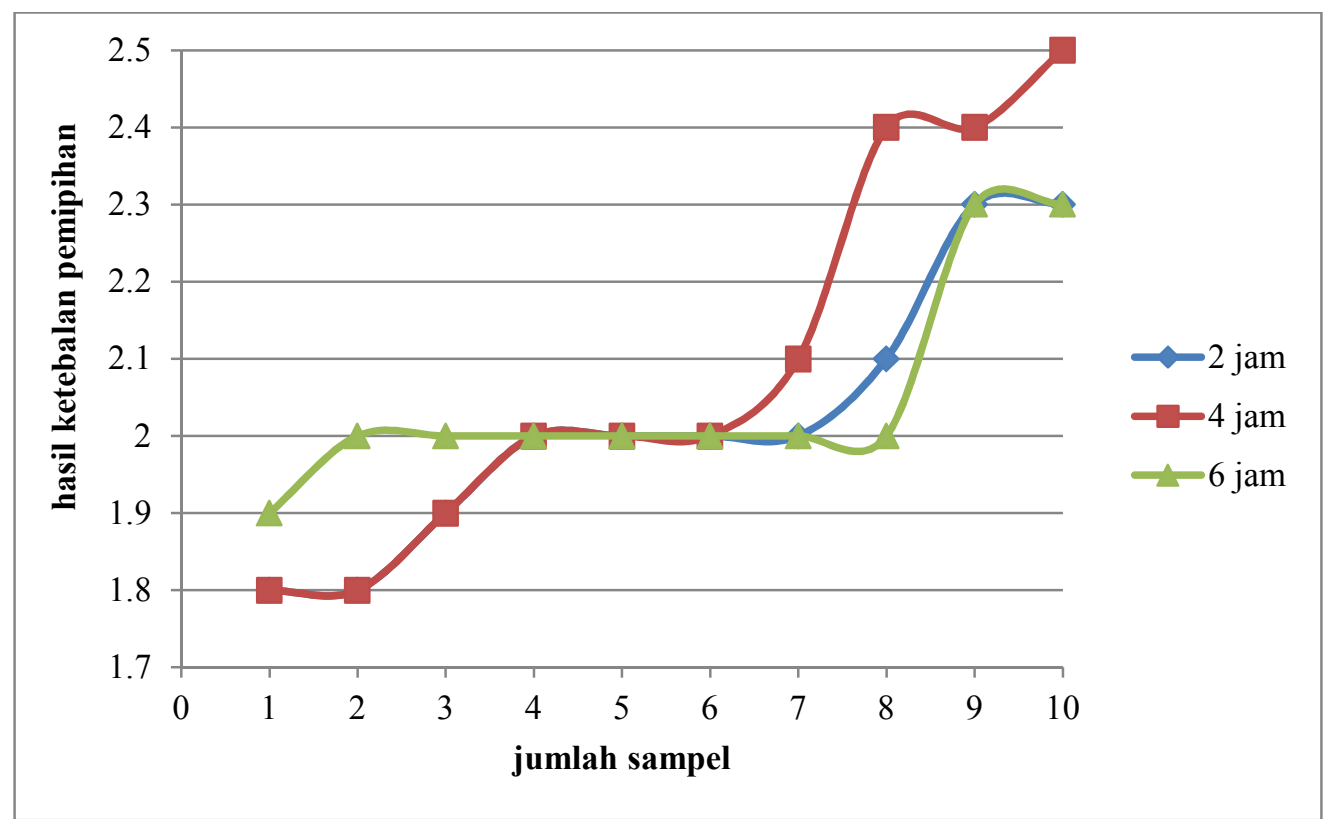

Gambar 5. Grafik hasil proses pemipihan untuk ketebalan \pm 2 mm selama 2 jam, 4 jam, dan 6 jam.

Untuk mengetahui seberapa besar tingkat keberhasilan dari alat tersebut maka dilakukan perhitungan kapasitas. Untuk pengujian pertama dengan ketebalan $\pm 1 \mathrm{~mm}$ dengan waktu pengeringan selama 2 jam.

$$
\begin{aligned}
\frac{1 k}{4 d} & =0,0023 \mathrm{~kg} / \text { detik } \times 3600 \\
& =8,28 \mathrm{~kg} / \mathrm{jam}
\end{aligned}
$$

Adapun hasil pemipihan untuk ketebalan $\pm 1,0 \mathrm{~mm}, \pm 1,5 \mathrm{~mm}$ dan $\pm 2,0 \mathrm{~mm}$ pengeringan selama 2 jam, 4 jam dan 6 jam menggunakan persamaan yang sama.

Tabel 1. Data hasil kapasitas produksi dengan ketebalan $\pm 1,0 \mathrm{~mm}, \pm 1,5 \mathrm{~mm}$ dan $\pm 2,0 \mathrm{~mm}$

Tabel 1. Data hasil kapasitas produksi dengan ketebalan $\mathbf{\pm} \mathbf{1 , 0} \mathbf{~ m m} \mathbf{\pm} \mathbf{1 , 5} \mathbf{~ m m}$ dan $\mathbf{\pm 2 , 0} \mathbf{~ m m}$
\begin{tabular}{|c|c|c|c|c|c|}
\hline No. & $\begin{array}{c}\text { Waktu } \\
\text { pengeringan }\end{array}$ & $\begin{array}{c}\text { Rata-rata hasil } \\
1\end{array}$ & $\begin{array}{c}\text { Kapasitas } \\
\text { jagung }(\mathrm{kg})\end{array}$ & $\begin{array}{c}\text { Waktu proses } \\
(\text { detik })\end{array}$ & $\begin{array}{c}\text { Kapasitas produksi } \\
(\mathrm{kg} / \mathrm{jam})\end{array}$ \\
\hline 1 & $2 \mathrm{jam}$ & $1,01 \mathrm{~mm}$ & 1 & 430 & 8,28 \\
\hline 2 & $4 \mathrm{jam}$ & $1,08 \mathrm{~mm}$ & 1 & 222 & 16,2 \\
\hline 3 & $6 \mathrm{jam}$ & $1,07 \mathrm{~mm}$ & 1 & 72 & 49,68 \\
\hline 4 & $2 \mathrm{jam}$ & $1,52 \mathrm{~mm}$ & 1 & 348 & 10,08 \\
\hline 5 & $4 \mathrm{jam}$ & $1,62 \mathrm{~mm}$ & 1 & 238 & 15,12 \\
\hline 6 & $6 \mathrm{jam}$ & $1,56 \mathrm{~mm}$ & 1 & 64 & 56,16 \\
\hline 7 & $2 \mathrm{jam}$ & $2,02 \mathrm{~mm}$ & 1 & 252 & 14,04 \\
\hline 8 & $4 \mathrm{jam}$ & $2,09 \mathrm{~mm}$ & 1 & 147 & 24,48 \\
\hline 9 & $6 \mathrm{jam}$ & $2,05 \mathrm{~mm}$ & 1 & 47 & 76,32 \\
\hline
\end{tabular}

Tabel di atas menunjukkan bahwa waktu pengeringan berpengaruh pada waktu proses pemipihan, dimana menunjukkan bahwa semakin lama di jemur semakin cepat proses pemipihan dan sedikit berpengaruh pada hasil pemipihan.

\section{KESIMPULAN DAN SARAN}

Berdasarkan hasil analisa data hasil pengujian alat Pemipih Mesin Biji Jagung dapat disimpulkan bahwa alat pemipih jagung yang dihasilkan dapat menghasilkan ketebalan pipih jagung $\pm 1 \mathrm{~mm}, \pm 1,5$ $\mathrm{mm}, \pm 2 \mathrm{~mm}$ dan untuk pembuatan alat pemipih jagung ini dibutuhkan baya sebesar Rp. 4.024.308. 
9 Simon Ka'ka, Jeremiah Ritto, Hasni, Mario F.L.N Juanto, Ghiyats Dzulkifli M. Rancang Bangun Alat Pemipih Biji Jagung Olahan

Adapun saran untuk memperbaiki rancangan selanjutnya yaitu perlu dilakukan penelitian lebih lanjut mengenai kadar air yang baik dalam proses pemipihan untuk menghasilkan ketebalan yang lebih maksimal dan putaran dapat divariasikan yang dapat mengatur ketebalan pemipihan.

\section{DAFTAR PUSTAKA}

AnekaMesin, 2005. Pemipih Emping Jagung.

Budi, Arifin. 2013. Jenis dan Klarifikasi Jagung. Blogspot.com

Budidaya Tanaman Jagung Super Hibrida. 2011. PT. Bisi internasional.tbk.

Basri, M dkk. 2011. Rancang Bangun Alat Penggiling Jagung Untuk Pakan Ternak Ayam Petelur. Politeknik Negeri Ujung Pandang. Makassar.

Camma, Herman. 2006. Rancang Bangun Alat Pemipih Buah Melinjo. Politeknik Negeri Ujung Pandang. Makassar.

Kamus Besar Bahasa Indonesia,Emping.

Khurmi. 1982. Machine Design, Eurasia Publishing,Hause, New Delhi.

Pengelolahan Emping Jagung, Pemetaan TTG - Ditjen PMD, Kementerian Dalam Negeri RI.

Priwit. 2008. Teknologi \& Kendalanya Emping Jagung.

Singer, Ferdinand L dan Andrew Pytel. 1995. Kekuatan Bahan. Erlangga. Jakarta

Setyawan,Arif. 2013. Proses Pembuatan Emping jagung di Teaching Factory AI Cooperation SMK Negeri 1 Temanggung.

Sularso dan Suga. 1991. Dasar Perencencanaan dan Pemilihan Elemen Mesin. PT. Pradnya Paramita. Jakarta.

Sularso. 1995. Elemen Mesin. Bandung. Pusat Pengembangan Pendidikan Politeknik.

Suryana, Achmad. 2005. Ekonomi Jagung Indonesia. Jakarta.

Wikipedia indonesia, 2014. Ensiklopedia Bebas Berbahasa Indonesia. Jagung. 